\title{
Sustentabilidade a partir do uso de selos de certificação ambiental em
} empreendimentos de Habitação Social

\author{
Sustainability from the use of environmental certification seals in Social Housing \\ projects
}

Sostenibilidad a partir del uso de sellos de certificación ambiental em proyectos de Vivienda Social

Isabela Macário Custódio Arquiteta e Urbanista, Aluna especial do PPG Design - UNESP, Brasil. bela.macario@hotmail.com

Priscilla Lacerda Duarte David Mestre em Arquitetura e Urbanismo, Aluna especial do PPG Design - UNESP, Brasil. pridavid@gmail.com

Tomas Queiroz Ferreira Barata Professor Doutor, USP, PPG Design - UNESP, Brasil. barata@usp.br 


\section{Revista Científica ANAP Brasil}

ISSN 1984-3240 - Volume 14, número 35, 2021

\section{RESUMO}

A indústria da construção civil é responsável por grande parcela do consumo de matéria-prima e de geração de resíduos. Soma-se a isso, a intensa produção formal de habitações de interesse social dos últimos anos no Brasil, possibilitadas pelo Programa Minha Casa Minha Vida, o que levanta o questionamento sobre a qualidade do que está sendo produzido e qual o impacto ambiental causado durante todo o ciclo de vida dessas construções. Nesse contexto, esse trabalho investiga como a questão da sustentabilidade vem sendo tratada no setor da construção civil no Brasil, com foco em empreendimentos de caráter social, a partir de uma abordagem qualitativa por meio de revisão bibliográfica e estudos de caso. 0 estudo aprofundou-se nas certificações ambientais, que atuam como forma de incentivo à adoção de estratégias de menor impacto ambiental, em prol de ambientes mais saudáveis e a fim de equiparar as avaliações nos edifícios verdes. Observou-se particularmente o Selo Casa Azul da Caixa, que apesar de possuir falhas, apresenta grande potencial de aplicabilidade em projetos de habitações sociais, como ferramenta no caminho para cidades menos impactantes ao meio.

PALAVRAS-CHAVE: Arquitetura e Construção Sustentável. Certificação Ambiental. Selo Casa Azul. Habitação de Interesse Social.

\section{ABSTRACT}

The civil construction factory is responsible for a large portion of raw material consumption and waste generation. Moreover, the intense formal production of social housing in Brazil in recent years, made possible by the Minha Casa Minha Vida Program, which raises the question about the quality of what is being produced and the environmental impact caused throughout the life cycle of these constructions. In this context, this work investigates how the issue of sustainability has been handled in the civil construction sector in Brazil, with a focus on social enterprises, from a qualitative approach through literature review and case studies. There was a thoroughgoing study about environmental certifications, which act as a way to encourage the adoption of strategies with less environmental impact, in favor of healthier environments and in order to match assessments in green buildings. Particularly, the Casa Azul da Caixa Seal was observed, which despite having flaws, has great potential for applicability in social housing projects, as a tool on the way to cities with less impact in the environment.

\section{RESUMEN}

La industria de la construcción civil es responsable de una gran parte del consumo de materias primas y la generación de residuos. A esto se suma la intensa producción formal de vivienda de interés social en Brasil en los últimos años, posibilitada por el Programa Minha Casa Minha Vida, que plantea el cuestionamiento sobre la calidad de lo que se está produciendo y el impacto ambiental causado a lo largo del ciclo de vida. de estas construcciones. En este contexto, este trabajo investiga cómo se ha abordado el tema de la sostenibilidad en el sector de la construcción civil en Brasil, con un enfoque en las empresas sociales, desde un enfoque cualitativo a través de la revisión de la literatura y estudios de caso. El estudio profundizó en las certificaciones ambientales, que actúan como una forma de incentivar la adopción de estrategias con menor impacto ambiental, a favor de ambientes más saludables y con el fin de igualar las evaluaciones en edificios verdes. En particular, se observó el Sello Casa Azul da Caixa, que a pesar de tener fallas, tiene un gran potencial de aplicabilidad en proyectos de vivienda social, como herramienta en el camino hacia las ciudades con menor impacto en el medio ambiente. 


\section{Revista Científica ANAP Brasil}

ISSN 1984-3240 - Volume 14, número 35, 2021

\section{INTRODUÇÃO}

As discussões sobre a questão da sustentabilidade, sobretudo pelo viés ambiental, se iniciam com a crise energética, na década de 70. No entanto, o assunto ainda é um grande desafio, principalmente em atividades econômicas tradicionais como é o caso da indústria da construção civil, que chegou a ser responsável por 6,5\% do PIB brasileiro em 2012 (DIEESE, 2020).

O setor envolve ainda outras grandes indústrias, como por exemplo a da extração e beneficiamento de minérios, se configurando como o principal consumidor de matérias primas da economia e o maior gerador de resíduos (JOHN, 2000).

Apesar da grande produção da construção civil, o país enfrenta a décadas a problemática do déficit habitacional, impulsionada pelo êxodo rural e o crescimento desordenado das cidades. Na tentativa de garantir habitação digna à população de baixa renda, foram implementadas políticas públicas, dentre elas se destaca o Programa Minha Casa Minha Vida, criado em 2009, com vigência até 2020. Nesse período foram entregues mais de cinco milhões de habitações, no entanto, dados do governo federal apontam déficit de ainda mais de cinco milhões de habitações urbanas (BRASIL, 2021).

A produção de construções nesse montante, por todo o território nacional, levanta o questionamento sobre a qualidade do que está sendo produzido. Diversas pesquisas tratam das características do projeto arquitetônico, aspectos urbanos e manifestações patológicas pós-ocupação. Todavia, pouco se fala do impacto dessas construções no meio ambiente, seja na implantação, durante ou ao final do ciclo de vida da edificação.

Nesse contexto se inserem os conceitos da Arquitetura e Construção Sustentável, que trazem discussões dentro do tripé econômico, social e ambiental e demonstram a preocupação do setor em prol da sustentabilidade. Particularmente, por meio das certificações verdes conferidas às construções, observa-se um grande marketing para que mais empresários do setor utilizem estratégias no caminho para cidades menos impactantes ao meio.

\section{OBJETIVOS}

Os objetivos desse trabalho se concentram na investigação de como a questão da sustentabilidade vem sendo tratada no setor da construção civil no Brasil, especialmente nos empreendimentos de habitação de interesse social, que tiveram grande aumento de produção nos últimos anos devido ao Programa Minha Casa Minha Vida. Além disso, tendo em vista a popularização das certificações ambientais, que atuam como incentivo a adoção de estratégias de menor impacto ambiental, traçou-se um panorama do uso dos selos de certificação ambiental em construções no país, com vistas ao uso na habitação de interesse social.

\section{METODOLOGIA/MÉTODO DE ANÁLISE}

Esse trabalho se caracteriza pela abordagem qualitativa. Por se tratar de pesquisa exploratória foram utilizados os métodos de revisão bibliográfica, a partir da análise de artigos, teses, dissertações, monografias e manuais técnicos sobre o tema, além de estudo de dois casos: 1. Residencial Ville Barcelona, localizado na cidade de Betim, Minas Gerais e 2. Condomínio E / G - Paraisópolis, localizado em São Paulo capital, ambos com certificação ambiental Casa Azul, analisando os as categorias: 1. Qualidade urbana, 2. Projeto e Conforto, 3. Eficiência Energética, 4. Conservação e Recursos Materiais, 5. Gestão da água e 6. Práticas Sociais 


\section{Revista Científica ANAP Brasil}

ISSN 1984-3240 - Volume 14, número 35, 2021

\section{RESULTADOS}

Para facilitar a compreensão, as análises foram divididas nas seguintes temáticas: Breve histórico da questão da habitação social no Brasil (item 4.1), Construção e Sustentabilidade (item 4.2) e Estudo de caso (item 4.3).

\subsection{Breve histórico da questão da habitação social no Brasil}

A questão habitacional no Brasil começou a ser analisada por volta da década de 1880, devido às grandes ameaças à saúde pública. Isso porque, a produção de moradias de caráter social não conseguia acompanhar o aumento acelerado da população nas cidades (BONDUKI,2017).

Apesar das diversas políticas públicas aplicadas, como financiamentos governamentais mediante o Instituto de Aposentadoria e Pensão (IAPs) e a Fundação da Casa Própria (FCP), não foi possível evitar a formação e adensamento de ocupações irregulares às margens das grandes cidades.

A Lei 4380/64 foi responsável pela criação do Sistema Financeiro da Habitação (SFH) e, por consequência, do Banco Nacional da Habitação (BNH), conhecido amplamente pela produção de moradias em massa. Isto gerou um enfraquecimento gradativo dos projetos habitacionais por manifestar apenas esforços para redução de custos e se esquecer de outras perspectivas que a arquitetura moderna propõe (BONDUKI, 2017).

Em 1986 o BNH foi extinto, mas outros programas habitacionais continuaram existindo como forma de reduzir os problemas urbanos. Entre eles, o Minha Casa Minha Vida (MCMV), com início em 2009. O programa surge como forma de socorrer o setor da construção civil e mercado imobiliário que sofria com a crise internacional do subprime de 2008. Inicialmente pensava-se em uma estratégia destinada apenas às famílias de estratos médios - com renda acima de três salários mínimos, já que o setor não queria correr riscos. Mas governistas intermediaram a entrada de famílias de menor renda, com subsídios públicos e o Programa passou a ser o eixo central da política habitacional no Brasil (KLINTOWITZ, 2016).

Em pouco mais de 10 anos de existência, o Programa entregou mais de 5 milhões de unidades. Apesar disso, o déficit habitacional absoluto do país está seguindo uma tendência de aumento. De 2016 a 2019, houve um aumento de mais de 219 mil entre os três componentes analisados: habitação precária, coabitação e ônus excessivo com aluguel urbano (FUNDAÇÃO JOÃO PINHEIRO, 2021). Dados do próprio governo federal apontam o déficit de ainda mais de 5 milhões de habitações (BRASIL, 2021).

Em agosto de 2020 foi lançado um Programa Casa Verde e Amarela, uma reformulação do MCMV, com o objetivo beneficiar com contratos de crédito imobiliário um total 1,6 milhão de famílias de baixa renda até 2024 (BRASIL, 2020).

É possível observar que a questão do déficit habitacional é de fato complexa de ser resolvida, já que envolve inúmeros atores sociais, exige organização e subsídios econômicos por parte do Estado. No entanto, mais do que produzir construções desenfreadamente, é importante assegurar moradias de cunho social de qualidade, e menos impactantes ao meio ambiente. 


\section{Revista Científica ANAP Brasil}

ISSN 1984-3240 - Volume 14, número 35, 2021

\subsection{Construção e Sustentabilidade}

O modelo de produção das construções no Brasil é ainda hoje bastante arcaico, com o uso em geral de materiais não renováveis e processos manuais, sendo comum haver desperdícios no canteiro de obras. Quando não há mais uso ou degradação excessiva, as construções são demolidas e os resíduos são descartados com pouco reaproveitamento. As habitações de interesse social repetem o mesmo método de construção, em baixo padrão.

Ao avaliar a indústria da construção civil, Barreto (2005) aponta que o setor produz grandes impactos ambientais, percebidos desde a extração das matérias-primas necessárias à fabricação de seus produtos, passando pela execução dos serviços nos canteiros de obra, até a destinação final dos resíduos gerados.

No que se refere especificamente às matérias-primas utilizadas, em geral provocam grande deterioração da paisagem natural, prejudicando a fauna e flora, além de demandar grandes quantidades de energia para beneficiamento e transporte.

Já no canteiro de obras, estima-se perdas e desperdício da matéria prima variando entre 20 e $30 \%$ da obra (PINTO, 1999), que podem ser causados pelo superdimensionamento, erros de armazenamento ou execução, quebra para passagem de tubulações etc., resultado da falta de padronização e racionalização dos processos.

Os resíduos gerados, somados aos resíduos de demolições representam até $70 \%$ (JOHN, 2000) dos resíduos sólidos urbanos. O descarte incorreto na zona urbana pode inclusive gerar áreas degradadas, o aumento da vulnerabilidade dos lençóis freáticos e rios ou córregos próximos, danos a espaços urbanos, perda da qualidade do ar por meio de ruídos ou poluição, insalubridades decorrentes da deposição de resíduos e danos à população das proximidades (ROTH; GARCIA, 2011).

Esses impactos se somam ao da fase operacional da edificação, quando os usuários utilizam energia elétrica para equipamentos diversos, gás natural para cocção, água e diversos produtos, que geram resíduos sólidos e esgoto.

Todos esses problemas ganharam maior notoriedade com a Conferência das Nações Unidas sobre Meio Ambiente e Desenvolvimento, a ECO-92 e 20 anos depois, a Rio+20 que culminaram em agendas que estabelecem objetivos para o desenvolvimento sustentável.

O tema sustentabilidade, em sua visão mais ampla, engloba os aspectos sociais, econômicos e ambientais. No que diz respeito à Arquitetura e Urbanismo, o tema começou a ser tratado, com ênfase no caráter ambiental, com estudo voltados à Arquitetura Bioclimática, a partir do desenvolvimento de estratégias de adaptação ao clima e local onde a construção se insere, tornando a construção naturalmente confortável, sem necessariamente o uso de aparatos elétricos, com uso racional dos recursos.

Assim em locais de clima quente e seco como no interior de São Paulo, é aconselhável, por exemplo, a proteção das aberturas da incidência solar direta, uso de materiais com baixa transmitância térmica e ventilação noturna, dentre outras estratégias, que somadas, permitem que o usuário esteja confortável em grande parte dos dias sem o uso de ar condicionado.

As preocupações referentes ao crescimento populacional e, consequentemente, a ampla utilização de recursos, contribuíram para um aumento no interesse de projetos construtivos que utilizassem uma Arquitetura Bioclimática, que hoje é amplamente difundida e disciplina obrigatória nos cursos de Arquitetura e Urbanismo. 


\section{Revista Científica ANAP Brasil}

ISSN 1984-3240 - Volume 14, número 35, 2021

Da mesma forma, a Arquitetura Sustentável visa a integração do edifício com o meio ambiente, considerando as condições locais em busca de melhor qualidade de vida. Corbella e Yannas (2009, p.19) consideram a Arquitetura Sustentável como "a continuidade mais natural da Bioclimática", ou seja, aquela que procura deixar um mundo melhor para as gerações futuras.

Nesse caso, há uma ampliação das discussões, abordando outras questões, como por exemplo: o impacto de extração, energia incorporada e ciclo de vida dos materiais, reuso de água, uso de equipamentos elétricos eficientes e de energia solar para aquecimento de água ou fotovoltaica, além da relação da construção com a cidade, que trata por exemplo da proximidade à equipamentos e transporte públicos e a salubridade do terreno.

Três princípios da sustentabilidade na arquitetura são propostos por Kim e Rigdon (1998). O primeiro é a economia de recursos, que busca reduzir, reusar e reciclar os materiais naturais utilizados em uma construção. O segundo é o design do ciclo de vida, que analisa o impacto ambiental de um edifício e o terceiro é o design humano, com foco na interação homem/natureza.

Estes elementos estão presentes na contemporaneidade em projetos de diferentes condições urbanas e ambientais, indicando que o baixo impacto ambiental pode ser alcançado com a recente arquitetura high-tech ou eco-tech, mas também está presente nas técnicas tradicionais da arquitetura vernacular (GONÇALVES; DUARTE, 2006), portanto, há ampla aplicabilidade dos conceitos da arquitetura sustentável.

\subsubsection{Certificação ambiental da construção}

Nesse contexto, os processos de certificação ambiental surgem como forma de incentivo à adoção de estratégias de menor impacto ambiental, em prol de ambientes mais saudáveis e a fim de equiparar as avaliações nos edifícios verdes. No Brasil existem hoje 3 selos de certificação mais conhecidos e aplicados: LEED, AQUA-HQE e Selo Casa Azul. As certificações estabelecem critérios de avaliação e pontuações e é necessária uma pontuação mínima para cumprir os requisitos.

Apesar de ainda pouco aplicados, se considerarmos a totalidade de construções feitas no Brasil, os selos de certificação em parte colaboraram para a disseminação das estratégias de arquitetura e construção sustentável. As empresas responsáveis por sua aplicação trabalham um grande marketing, valorizando os benefícios econômicos que o empreendedor e o comprador terão, que vendem o conceito verde e que acabam, em um segundo momento, levantando a discussão sobre os ganhos ambientais para toda a sociedade.

Esse conhecimento, que antes era restrito ao meio acadêmico, tem chegado até o consumidor final que pode pressionar o setor da construção civil a mudanças mais rápidas.

O selo LEED (Leadersheip in Energy and Enviromental Design) foi formulado na década de 90 pelo USGBC (United States Greeen Building Council), inicialmente pensado para avaliar a fase operacional da edificação, principalmente edifícios comerciais, a partir de um checklist que confere pontuações. A pontuação mínima para ser certificado é de 40 pontos, a partir de 50 pontos, o empreendimento recebe o selo Prata, a partir de 60 pontos, o selo Ouro e a partir de 80 pontos, o selo Platina. A certificação passou por revisões e hoje se divide em quatro tipologias: BUILDING DESIGN + CONSTRUCTION (novas construções e grandes reformas); INTERIOR DESIGN + CONSTRUCTION (escritórios comerciais e lojas de varejo); 


\section{Revista Científica ANAP Brasil}

ISSN 1984-3240 - Volume 14, número 35, 2021

OPERATION \& MAINTENANCE (empreendimentos existentes) e NEIGHBORHOOD (bairros). Dentro de cada tipologia são analisadas 8 áreas: Localização e Transporte, Espaço Sustentável, Eficiência do uso da água, Energia e Atmosfera, Materiais e Recursos, Qualidade Ambiental Interna, Inovação e Processos, Créditos de Prioridade Regional (GREEN COUNCIL BRASIL, c2021).

Os benefícios no uso desse selo incluem fatores econômicos, ambientais e sociais como por exemplo: a diminuição dos custos operacionais, a valorização do imóvel para revenda ou aluguel, uso racional e redução da extração dos recursos naturais, redução do consumo de água e energia, melhora na segurança e priorização da saúde dos trabalhadores e ocupantes e inclusão social e aumento do senso de comunidade (GREEN COUNCIL BRASIL, c2021).

Já a certificação AQUA-HQE foi lançada em 2008 e desenvolvida a partir da certificação francesa Démarche HQE (Haute Qualité Environnementale), adaptada ao contexto brasileiro, é aplicada pela Fundação Vanzolini. Nesse caso, além do estabelecimento de um sistema de gestão específico para o empreendimento, o empreendedor deve realizar a avaliação da qualidade ambiental do edifício em pelo menos três fases (construção nova e renovações): Pré-projeto, Projeto e Execução; na fase pré-projeto da Operação e Uso e fases Operação e Uso periódicas (edifício em operação e uso). A avaliação da Qualidade Ambiental do Edifício é feita para cada uma das 14 categorias de preocupação ambiental: relação do edifício com o seu entorno; escolha integrada de produtos, sistemas e processos construtivos; canteiro de obras de baixo impacto ambiental; gestão da energia; gestão da água; gestão de resíduos de uso e operação do edifício; manutenção - permanência do desempenho ambiental; conforto higrotérmico; conforto acústico; conforto visual; conforto olfativo; qualidade sanitária dos ambientes; qualidade sanitária do ar; qualidade sanitária da água. A classificação é feita nos níveis BASE, BOAS PRÁTICAS ou MELHORES PRÁTICAS, conforme perfil ambiental definido pelo empreendedor na fase pré-projeto (FUNDAÇÃO VANZOLINI, c.2015).

Os benefícios do selo AQUA-HQE incluem fatores ao empreendedor, ao usuário e à sociedade e meio ambiente, como por exemplo: manter o valor do patrimônio ao longo do tempo, associar a imagem da empresa à alta qualidade ambiental, economia direta no consumo de água e de energia elétrica, melhores condições de conforto e saúde ao usuário, menor demanda sobre as infraestruturas urbanas e diminuição da poluição (FUNDAÇÃO VANZOLINI, c2015).

Já o selo Casa Azul + CAIXA foi elaborado pela Caixa em parceria com professores da UFSC, USP e Unicamp em 2010 e passou por uma revisão em 2020. Possui 4 níveis de gradação - Bronze, Prata, Ouro e Diamante - concedidos conforme a pontuação alcançada nos 49 critérios de avaliação existentes, somada à pontuação Bônus. O selo se constitui no primeiro sistema de classificação da sustentabilidade de projetos desenvolvido para a realidade da construção habitacional brasileira e é destinado a propostas de empreendimentos habitacionais, financiadas pela Caixa, que adotem soluções eficientes na concepção, execução, uso, ocupação e manutenção das edificações. Os critérios de avaliação estão distribuídos nas Categorias "Qualidade Urbana e Bem-estar", "Eficiência Energética e Conforto Ambiental", "Gestão Eficiente da Água", "Produção Sustentável", "Desenvolvimento Social" e "Inovação". Existem 15 critérios obrigatórios à obtenção dos Selos Bronze, Prata e Ouro (CAIXA ECONOMICA FEDERAL, 2020).

Neste trabalho foram considerados os critérios anteriores a revisão do selo Casa Azul, 
visto que os empreendimentos analisados no estudo de caso antecedem o ano de 2020. Dessa forma, para melhor compreensão, os critérios pertencentes a cada categoria, bem como a sinalização daqueles considerados obrigatórios estão representados no Quadro 1.

Quadro 1 - Categorias de análise do selo Casa Azul

\begin{tabular}{|c|c|c|}
\hline \multicolumn{2}{|r|}{ Categoria } & \multirow{2}{*}{$\begin{array}{c}\text { Critérios } \\
\text { Obrigatórios }\end{array}$} \\
\hline 1 & Qualidade Urbana & \\
\hline 1.1 & Qualidade do Entorno - Infraestrutura & $x$ \\
\hline 1.2 & Qualidade do Entorno - Impactos & $x$ \\
\hline 1.3 & Melhorias no Entorno & \\
\hline 1.4 & Recuperação de Áreas Degradadas & \\
\hline 1.5 & Reabilitação de Imóveis & \\
\hline 2 & \multicolumn{2}{|l|}{ Projeto e Conforto } \\
\hline 2.1 & Paisagismo & $x$ \\
\hline 2.2 & Flexibilidade de Projeto & \\
\hline 2.3 & Relação com a Vizinhança & \\
\hline 2.4 & Solução Alternativa de Transporte & \\
\hline 2.5 & Local para coleta seletiva & $x$ \\
\hline 2.6 & Equipamentos de Lazer, Sociais e Esportivos & $x$ \\
\hline 2.7 & Desempenho Térmico - Vedações & $x$ \\
\hline 2.8 & Desempenho Térmico - Orientação ao Sol e Ventos & $x$ \\
\hline 2.9 & Iluminação Natural de Áreas Comuns & \\
\hline 2.10 & Ventilação e lluminação Natural de Banheiros & \\
\hline 2.11 & Adequação às Condições Físicas do Terreno & \\
\hline 3 & \multicolumn{2}{|l|}{ Eficiência Energética } \\
\hline 3.1 & Lâmpadas de Baixo Consumo - Áreas Privativas & $\begin{array}{c}\text { x (para HIS - } 0 \text { a } \\
3 \text { s.m.) }\end{array}$ \\
\hline 3.2 & Dispositivos Economizadores - Áreas Comuns & $\mathrm{x}$ \\
\hline 3.3 & Sistema de Aquecimento Solar & \\
\hline 3.4 & Sistemas de Aquecimento à Gás & \\
\hline 3.5 & Medição Individualizada - Gás & $x$ \\
\hline 3.6 & Elevadores Eficientes & \\
\hline 3.7 & Eletrodomésticos Eficientes & \\
\hline 3.8 & Fontes Alternativas de Energia & \\
\hline 4 & \multicolumn{2}{|l|}{ Conservação de Recursos Materiais } \\
\hline 4.1 & Modulação de Projeto & \\
\hline 4.2 & Qualidade de Materiais e Componentes & $x$ \\
\hline 4.3 & Componentes Industrializados ou Pré-fabricados & \\
\hline 4.4 & Formas e Escoras Reutilizáveis & $x$ \\
\hline 4.5 & Gestão de Resíduos de Construção de Demolição - RCD & $x$ \\
\hline 4.6 & Concreto com Dosagem Otimizada & \\
\hline 4.7 & Cimento de Alto Forno (CPIII) e Pozolânico (CP IV) & \\
\hline 4.8 & Pavimentação com RCD & \\
\hline 4.9 & Facilidade de Manutenção da Fachada & \\
\hline 4.10 & Madeira Plantada ou Certificada & \\
\hline 5 & Gestão da Água & \\
\hline 5.1 & Medição Individualizada - Água & $x$ \\
\hline 5.2 & Dispositivos Economizadores - Sistema de Descarga & $\mathrm{x}$ \\
\hline 5.3 & Dispositivos Economizadores - Arejadores & \\
\hline 5.4 & Dispositivos Economizadores - Outros Reguladores de Vazão & \\
\hline 5.5 & Aproveitamento de Águas Pluviais & \\
\hline 5.6 & Retenção de Águas Pluviais & \\
\hline 5.7 & Infiltração de Águas Pluviais & \\
\hline 5.8 & Áreas Permeáveis & $x$ \\
\hline 6 & Práticas Sociais & \\
\hline 6.1 & Educação para a Gestão de Resíduos de Construção e Demolição - RCD & $\mathrm{x}$ \\
\hline 6.2 & Educação Ambiental dos Empregados & $x$ \\
\hline 6.3 & Desenvolvimento Pessoal dos Empregados & \\
\hline
\end{tabular}




\begin{tabular}{|r|l|c|}
6.4 & Capacitação Profissional dos Empregados & \\
\hline 6.5 & Inclusão de Trabalhadores Locais & \\
\hline 6.6 & Participação da Comunidade na Elaboração do Projeto & $\mathrm{X}$ \\
\hline 6.7 & Orientação aos Moradores & \\
\hline 6.8 & Educação Ambiental dos Moradores & \\
\hline 6.9 & Capacitação para Gestão do Empreendimento & \\
\hline 6.10 & Ações para Mitigação de Riscos Sociais & \\
\hline 6.11 & Ações para a Geração de Emprego e Renda & \\
\hline
\end{tabular}

Fonte: Elaborado a partir de CAIXA ECONÔMICA FEDERAL, 2021.

A certificação hoje já foi concedida a 51 empreendimentos, dentre eles alguns que beneficiam pessoas de baixa renda, em parceria com construtoras e Prefeituras. $O$ incentivo para obtenção da certificação para o construtor e compradores é a redução na taxa de juros do financiamento e para a sociedade e o meio ambiente é a construção de empreendimentos habitacionais que priorizam o uso racional de recursos naturais na construção, adotam soluções urbanísticas e arquitetônicas de qualidade, promovam o desenvolvimento social e que se integrem à área de intervenção trazendo impactos positivos (CAIXA ECONOMICA FEDERAL, 2020).

Grünberg et al. (2014) por meio de Análise Hierárquica (Analytic Hierarchic Process) comparou os três selos verdes e o sistema de certificação ambiental Selo Casa Azul, desenvolvido para a realidade brasileira, teve maior nota final. Em segundo lugar, tem-se o AQUA, adaptação de um sistema estrangeiro para a realidade brasileira e por último, o selo LEED, que é utilizado conforme foi concebido, aparece com menor índice de desempenho.

Bueno e Rossignolo (2010) apontam ainda que, apesar de o LEED ter um sistema avaliativo de aplicação simplificada na forma de checklist, foi desenvolvido para o contexto nacional específico dos Estados Unidos, o que limita seu uso em diferentes países, como o Brasil, por não apresentar capacidade suficiente de adaptação a diferentes contextos locais. No caso do AQUA, sua estruturação em questionário aplicado por terceiros e sua adaptação ao contexto brasileiro deveriam tornar esse o método mais aplicado. Entretanto, a falta de divulgação em torno dessa certificação, somada aos altos custos do processo se traduzem em pouca aplicabilidade.

Nesse cenário, o Selo Casa Azul tem destaque na habitação social, além dos pontos elencados pelos autores, é preciso considerar que a Caixa detém quase $70 \%$ do mercado de financiamentos no Brasil, base da política de habitação social no país, portanto demonstrando o grande potencial de crescimento na aplicação da certificação.

Por se tratar de edificações de baixo padrão, que pressupõe economia financeira, é possível que inicialmente haja resistência do empreendedor na aplicação do selo, no entanto, análise de Silva (2017) sobre os custos da implantação do selo em um projeto de um pequeno condomínio com cinco residências mostraram aumento de apenas 5,22\% em relação ao custo inicial. Apesar do projeto certificado apresentar uma despesa maior, é possível afirmar que a curto prazo o empreendimento apresenta vantagens econômicas, tais como: menor consumo de energia, economia de água e conforto térmico devido às vedações (SILVA, 2017). Além disso, a Caixa fornece descontos na taxa de juros tanto para o empreendedor que financia a construção do empreendimento, como para o adquirente, que compra uma unidade habitacional, o que também dilui, a longo prazo, o maior valor investido.

Dessa forma, optou-se por analisar dois projetos certificados pelo Selo Casa Azul, como estudo de caso, com vistas à sua utilização como ferramenta pelo projetista na tomada 


\section{Revista Científica ANAP Brasil}

ISSN 1984-3240 - Volume 14, número 35, 2021

de decisão na elaboração de projetos de habitação de interesse social.

\subsection{Estudo de caso}

Os projetos do Residencial Ville Barcelona, localizado na cidade de Betim, Minas Gerais (item 4.3.1) e Condomínio E / G - Paraisópolis, localizado em São Paulo capital (item 4.3.2) foram analisados a partir dos critérios atendidos para obtenção do Selo Casa Azul.

\subsubsection{Residencial Ville Barcelona (Betim - Minas Gerais)}

O Residencial Ville Barcelona está localizado na cidade de Betim, Minas Gerais (figura 1). O edifício foi desenvolvido pela Construtora Precon Engenharia e em parceria com a Creato Consultoria e Projeto foi possível a obtenção do Selo Casa Azul, da Caixa Econômica Federal, sendo o primeiro empreendimento do Programa Minha Casa Minha Vida (PMCMV) a receber a certificação sustentável.

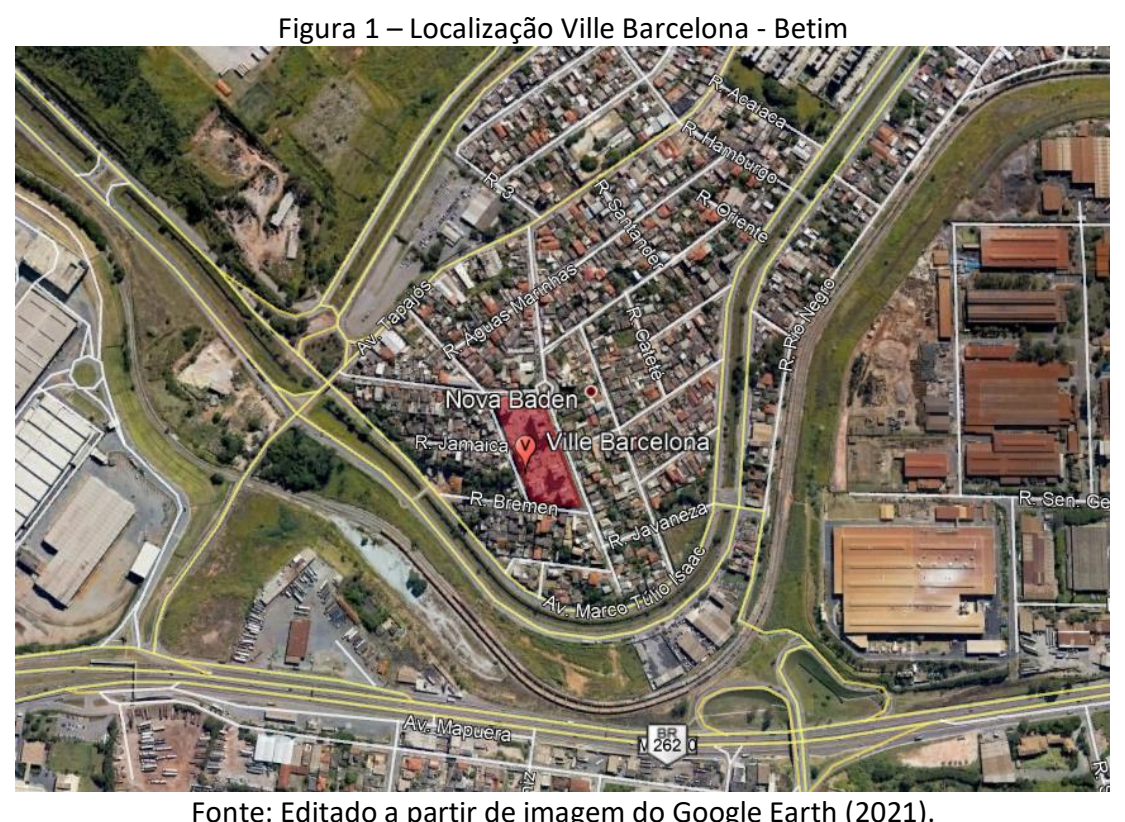

De acordo com a Creato Consultoria e Projetos (2021), o empreendimento abriga 30 famílias em um edifício com 8 pavimentos. Cada unidade habitacional é composta por dois dormitórios, tendo uma área útil de, aproximadamente $43 \mathrm{~m}^{2}$ (figura 2).

Ainda segundo a Creato (2021), o processo construtivo foi essencial para economia na geração de resíduos e eficiência do empreendimento. Além disso, como a intenção de certificar o residencial se iniciou durante a fase de projeto, foi possível avaliar quais critérios se adequavam à obra em relação ao custo-benefício para serem adotados.

Dessa forma, foram atendidos 29 critérios de avaliação dos 53 disponíveis - de acordo com as diretrizes originais, anteriores a atualização de 2020 - (quadro 2) sendo 18 de caráter obrigatório e 11 de livre escolha. 


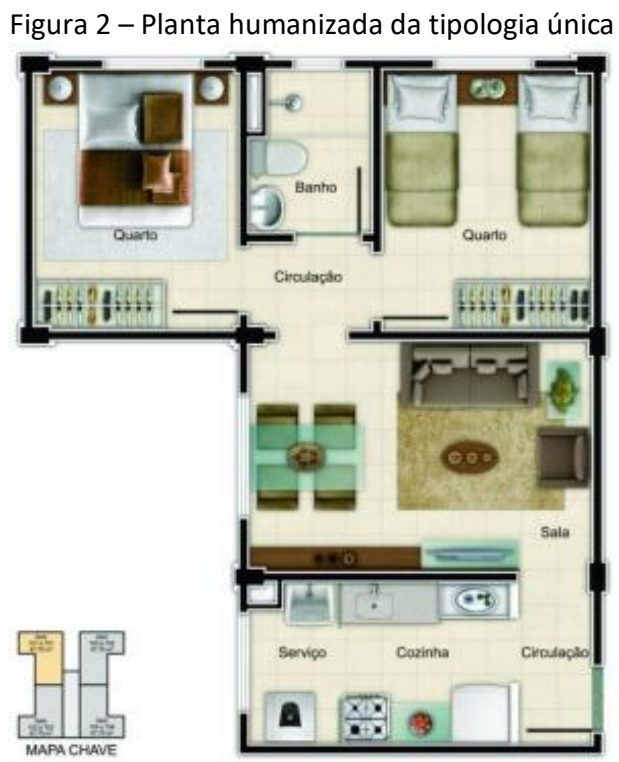

Fonte: SANTOS apud PRECON, 2017.

Quadro 2-Categorias de análise do selo Casa Azul

\begin{tabular}{|l|l|}
\hline \multicolumn{1}{|c|}{ Categoria } & \multicolumn{1}{c|}{ Critérios atendidos } \\
\hline $\begin{array}{l}\text { 1. Qualidade } \\
\text { Urbana }\end{array}$ & Qualidade do entorno - Infraestrutura / Impactos; Melhorias no entorno. \\
\hline $\begin{array}{l}\text { 2. Projeto e } \\
\text { Conforto }\end{array}$ & $\begin{array}{l}\text { Paisagismo; Flexibilidade de projeto; Local para coleta seletiva; Equipamentos de lazer, sociais e } \\
\text { esportivos; Desempenho térmico - Vedações, Orientação ao sol e ventos; Ventilação e } \\
\text { iluminação natural de banheiros. }\end{array}$ \\
\hline $\begin{array}{l}\text { 3. Eficiência } \\
\text { Energética }\end{array}$ & $\begin{array}{l}\text { Dispositivos economizadores - Áreas comuns; Medição individualizada - Gás; Elevadores } \\
\text { eficientes. }\end{array}$ \\
\hline $\begin{array}{l}\text { 4. Conservação } \\
\text { de Recursos } \\
\text { Materiais }\end{array}$ & $\begin{array}{l}\text { Qualidade de materiais e componentes; Componentes industrializados ou pré-fabricados; } \\
\text { Formas e escoras reutilizáveis; Gestão de resíduos de construção de demolição - RCD; Concreto } \\
\text { com dosagem otimizada; Cimento de alto forno (CP III) e pozolâmico (CP IV); Madeira plantada } \\
\text { ou certificada. }\end{array}$ \\
\hline $\begin{array}{l}\text { 5. Gestão da } \\
\text { Água }\end{array}$ & $\begin{array}{l}\text { Medição individualizada - Água; Dispositivos economizadores - Sistema de descarga; } \\
\text { Arejadores; Áreas permeáveis. }\end{array}$ \\
\hline $\begin{array}{l}\text { 6. Práticas } \\
\text { Sociais }\end{array}$ & $\begin{array}{l}\text { Educação para a gestão de resíduos de construção e demolição - RCD; Educação } \\
\text { ambiental/Desenvolvimento pessoal dos empregados; Inclusão de trabalhadores locais e } \\
\text { Orientação aos moradores. }\end{array}$ \\
\hline
\end{tabular}

A Construtora responsável trabalha a partir de um modelo de construção off site, ou seja, fora do canteiro de obras. Para isso, o processo de inicia em fábrica, com a produção de vigas, pilares e pré-lajes em concreto e fabricação dos painéis de vedação em tijolo cerâmico revestido em concreto. Só então as peças são transportadas para o local da obra para montagem. O método construtivo foi nomeado Solução Habitacional Precon, e instituíram a sustentabilidade como principal ponto de geração de benefícios se comparado ao modo tradicional de construção.

Esse método, aliado a produção em larga escala, diminui o tempo de construção e o custo da mão de obra, por necessitar de menos colaboradores, uma vez que a maioria das peças são desenvolvidas em fábrica. Isto, além de otimizar processos, gera menos impactos ambientais, reduzindo cerca de $85 \%$ os resíduos gerados (PRECON, c2019).

A partir das constatações acerca deste projeto podemos perceber que mesmo com 


\section{Revista Científica ANAP Brasil}

ISSN 1984-3240 - Volume 14, número 35, 2021

muitas soluções simples, como a especificação de dispositivos economizadores de água e de energia, as escolhas assertivas tiveram grande importância para que o Edifício Ville Barcelona obtivesse o Selo Casa Azul na gradação Prata.

\subsection{Condomínio E / G - Paraisópolis}

O conjunto habitacional de Paraisópolis está localizado em São Paulo capital (figura 3) e foi pensado para abrigar cerca de 1.000 famílias durante o processo de reurbanização da favela de mesmo nome. Ele é composto por sete condomínios independentes entre si, formados a partir de módulos conectáveis. Ao todo são 42 edifícios modulares e 954 Unidades Habitacionais (ELITO ARQUITETOS, 2021).

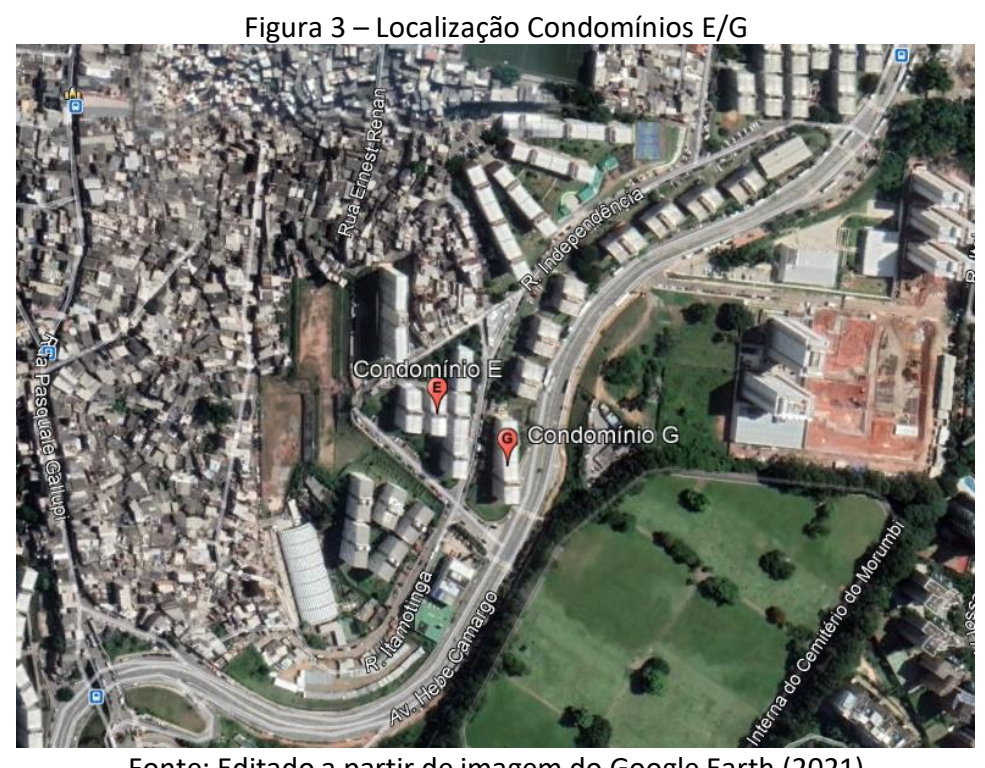

Fonte: Editado a partir de imagem do Google Earth (2021)

Figura 4 - Planta da Unidade Habitacional

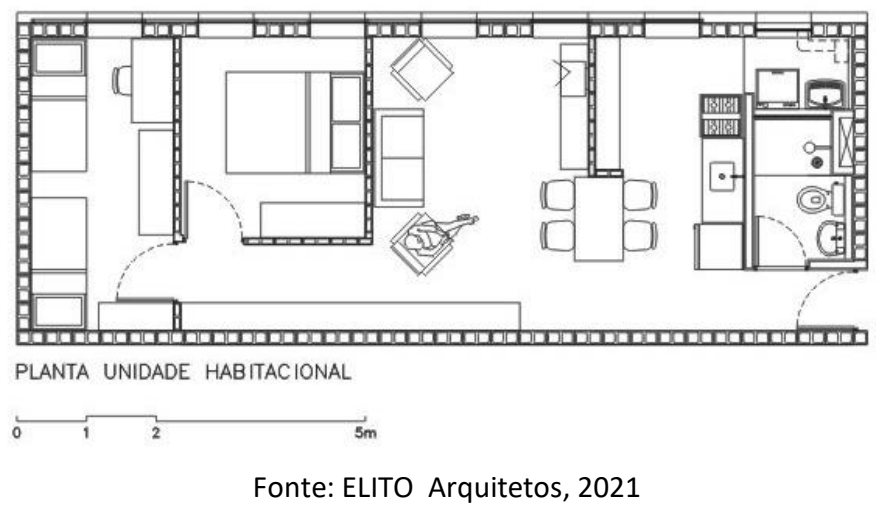

Os blocos analisados por este estudo são os E e G, que conseguiram obter o Selo Casa Azul. Suas tipologias possuem 2 dormitórios, tendo uma área total aproximada de $54 \mathrm{~m}^{2}$ (figura 4). Entretanto, a planta da unidade possui flexibilidade na alteração de layout, visto que todas as paredes internas podem ser reposicionadas (ELITO ARQUITETOS, 2021).

Para obtenção do certificado de construção sustentável na gradação Ouro, os 


\section{Revista Científica ANAP Brasil}

ISSN 1984-3240 - Volume 14, número 35, 2021

condomínios pertencentes ao programa PAC urbanização de Favelas, com 117 Unidades Habitacionais cumpriram 39 critérios (quadro 3) sendo 19 de caráter obrigatório e 20 de livre escolha.

Quadro 3-Categorias de análise do selo Casa Azul

\begin{tabular}{|l|l|}
\hline \multicolumn{1}{|c|}{ Categoria } & \multicolumn{1}{c|}{ Critérios atendidos } \\
\hline $\begin{array}{l}\text { Urbana } \\
\text { 2. Projeto e } \\
\text { Conforto }\end{array}$ & $\begin{array}{l}\text { Qualidade do entorno - Infraestrutura e Impactos; Melhorias no entorno; Recuperação de áreas } \\
\text { degradadas. }\end{array}$ \\
\hline $\begin{array}{l}\text { 3. Eficiência } \\
\text { Energertives; } \\
\text { Iluminação natural de áreas comuns; Adequação às condições físicas do terreno. }\end{array}$ & $\begin{array}{l}\text { Lâmpadas de baixo consumo - Áreas privativas; Dispositivos economizadores - Áreas comuns; } \\
\text { Medição individualizada - Gás. }\end{array}$ \\
\hline $\begin{array}{l}\text { 4. Conservação } \\
\text { de Recursos } \\
\text { Materiais }\end{array}$ & $\begin{array}{l}\text { Modulação de projeto; Qualidade de materiais e componentes; Componentes industrializados } \\
\text { ou pré-fabricados; Formas e escoras reutilizáveis; Gestão de resíduos de construção de } \\
\text { demolição - RCD; Concreto com dosagem otimizada; Facilidade de manutenção da fachada. }\end{array}$ \\
\hline $\begin{array}{l}\text { 5. Gestão da } \\
\text { Água }\end{array}$ & $\begin{array}{l}\text { Medição individualizada - Água; Dispositivos economizadores - Sistema de descarga, } \\
\text { Arejadores, Outros reguladores de vazão; Retenção de águas pluviais; Áreas permeáveis. }\end{array}$ \\
\hline $\begin{array}{l}\text { 6. Práticas } \\
\text { Sociais }\end{array}$ & $\begin{array}{l}\text { Educação para a gestão de resíduos de construção e demolição - RCD; Educação } \\
\text { ambiental/Desenvolvimento pessoal/Capacitação profissional dos empregados; Inclusão de } \\
\text { trabalhadores locais; Participação da comunidade na elaboração do projeto; } \\
\text { Orientação/Educação ambiental dos moradores; Capacitação para gestão do empreendimento; } \\
\text { Ações para mitigação de riscos sociais; Ações para a geração de emprego e renda. }\end{array}$ \\
\hline
\end{tabular}

Fonte: Elaborado a partir de dados obtidos da CAIXA ECONÔMICA FEDERAL, 2021.

Uma característica importante deste projeto é a participação ativa dos moradores, que por meio de reuniões e conselhos conseguiram demonstrar suas opiniões como a opção por permanecer próximo à favela em questão (FIGUEIREDO, 2018).

Outro ponto para se considerar é, novamente, o sistema construtivo. Diferente do Ville Barcelona, este projeto adotou o sistema estrutural de paredes portantes em alvenaria de blocos de concreto nas extremidades dos blocos, permitindo que as internas as unidades tenham o único objetivo de separação de ambientes, por este motivo podendo ser alteradas (ELITO ARQUITETOS, 2021).

De acordo com Figueiredo (2018, p. 129) as adaptações ao projeto original geraram um acréscimo de aproximadamente $1 \%$ no custo final da obra, e "considerando que este é um contexto em que a habitação é de interesse social o aumento pouco significativo no orçamento tornou possível a certificação".

Dessa forma, o projeto mostra que é possível adequar soluções mais sustentáveis em obras de cunho social para aquisição do Selo desenvolvido pela Caixa.

\section{CONCLUSÃO}

Conforme aponta John (2000), não será possível um desenvolvimento sustentável na cadeia produtiva da construção civil sem que haja transformações estruturais significativas, o que demandará ação conjunta da sociedade em busca de soluções e exigirá uma mudança de cultura e comportamento. Para isso, será preciso extenso planejamento, para que o setor não sofra danos econômicos. No entanto, é preciso pensar o que pode ser feito a curto prazo diante da problemática ambiental.

A pesquisa acerca da sustentabilidade na produção formal de habitação social no 


\section{Revista Científica ANAP Brasil}

ISSN 1984-3240 - Volume 14, número 35, 2021

Brasil mostrou o potencial de uso do Selo Casa Azul da Caixa. Saindo do âmbito de projetos financiados pelo banco, o material elaborado é completo, com participações de grandes universidades brasileiras e faz um compilado das Normas NBR 15220 - parte 3 - Zoneamento bioclimático brasileiro e diretrizes construtivas para habitações unifamiliares de interesse social (ABNT, 2005) e NBR 15575 - Edificações habitacionais - Desempenho (ABNT, 2013), dessa forma, se configurando como uma ferramenta importante para projetistas na tomada de decisões.

Muitos das estratégias apontadas são simples de serem executadas, e muitas vezes essenciais para o bem-estar dos moradores, como a elaboração de um projeto paisagístico, local para coleta seletiva e desempenho térmico das unidades, com pouco acréscimo aos custos da obra, que inclusive gera retorno a médio e longo prazo.

O selo tem falhas, não faz menção por exemplo aos impactos da extração dos materiais utilizados e sua energia incorporada. Entretanto, é uma iniciativa importante e merece ampla implantação nos edifícios de baixa renda, para trazerem mais qualidade de vida aos usuários e benefícios a toda a sociedade e o planeta.

\section{REFERÊNCIAS BIBLIOGRÁFICAS}

ASSOCIAÇÃO BRASILEIRA DE NORMAS TÉCNICAS (ABNT). NBR 15220 - 3: Desempenho térmico de edificações residenciais. Parte 3 - Zoneamento bioclimático brasileiro e diretrizes construtivas para habitações unifamiliares de interesse social. Rio de Janeiro, ABNT, 2005.

ASSOCIAÇÃO BRASILEIRA DE NORMAS TÉCNICAS (ABNT). NBR 15575 - Edificações habitacionais - Desempenho. Rio de Janeiro, ABNT, 2013.

BARRETO, I. M. C. B. N.. Gestão de resíduos na construção civil. Sergipe: Sinduscon, 2005.

BONDUKI, N.. Origens da habitação social no Brasil: arquitetura moderna, lei do inquilinato e difusão da casa própria. 7. ed. São Paulo: Estação Liberdade, 2017.

BRASIL. Governo Federal. Ministério do Desenvolvimento Regional. Casa Verde e Amarela vai financiar 1,6 mil imóveis, regularizar 2 milhões de moradias e reformar 400 mil até 2024 . Disponível em: https://www.gov.br/mdr/pt-br/noticias/casa-verde-e-amarela-vai-financiar-1-6-mil-imoveis-regularizar-2-milhoesde-moradias-e-reformar-400-mil-ate-2024. Acesso em 06 abr. 2021.

BRASIL. Governo Federal. Ministério do Desenvolvimento Regional. SISHAB. Disponível em: http://sishab.mdr.gov.br/. Acesso em 15 abr. 2021.

BUENO, C.; ROSSIGNOLO, J. A.. Desempenho ambiental de edificações: cenário atual e perspectivas dos sistemas de certificação. Minerva, v. 7, n. 1, p. 45-52, $2010 . \quad$ Disponível em: http://www.fipai.org.br/Minerva\%2007(01)\%2006.pdf. Acesso em: 20 abr. 2021.

CAIXA ECONÔMICA FEDERAL. Guia Selo Casa Azul + Caixa. Caixa Econômica Federal, jun. 2020. Disponível em: https://www.caixa.gov.br/sustentabilidade/negocios-sustentaveis/selo-casa-azul-caixa/Paginas/default.aspx.

Acesso em 04 maio 2021.

CAIXA ECONÔMICA FEDERAL. Selo Casa Azul: Boas práticas para habitação mais sustentável. São Paulo: Páginas \& Letras - Editora e Gráfica, 2010. Disponível em: https://labeee.ufsc.br/projetos/manual-selo-casa-azul-caixa. Acesso em 04 maio 2021.

CORBELLA, O.; YANNAS, S. Em busca de uma arquitetura sustentável para os trópicos: conforto ambiental. 2. ed. Rio de Janeiro: Revan, 2009. 308 p.

CREATO. Creato Consultoria e Projetos. Certificação - Selo Casa Azul da CEF: Projeto certificado em sustentabilidade ambiental, 2021. Disponível em: https://www.creato.com.br/ville-barcelona. Acesso em 03 maio 2021. 


\section{Revista Científica ANAP Brasil}

ISSN 1984-3240 - Volume 14, número 35, 2021

DIEESE - Departamento Intersindical de Estatística e Estudos Socioeconômicos. A Construção Civil e os Trabalhadores: panorama dos anos recentes In: Estudos e Pesquisas, n. 95, jul. 2020. Disponível em: https://www.dieese.org.br/estudosepesquisas/2020/estPesq95trabconstrucaocivil/index.html?page=1. Acesso em 04 abr. 2021

ELITO ARQUITETOS. Programa Habitacional Paraisópolis, 2021. Disponível em: http://elitoarquitetos.com.br/programa-habitacional-paraisopolis.html. Acesso em 04 maio 2021

FIGUEIREDO, A. C. C.. Certificação ambiental e habitação no Brasil: agentes e requisitos urbanísticos e arquitetônicos. 2018. 182 f. Dissertação (Mestrado) - Curso de Arquitetura e Urbanismo, Instituto de Arquitetura e Urbanismo, Universidade de São Paulo, São Carlos, 2018. Disponível em: https://teses.usp.br/teses/disponiveis/102/102131/tde-18022019-105333/pt-br.php. Acesso em: 05 maio 2021.

FUNDAÇÃO JOÃO PINHEIRO. Déficit habitacional no Brasil - 2016-2019 / Fundação João Pinheiro. - Belo Horizonte: FJP, 2021. 169 p.: il. Disponível em http://novosite.fjp.mg.gov.br/wp-content/uploads/2020/12/04.03_RelatorioDeficit-Habitacional-no-Brasil-2016-2019-v1.0_compressed.pdf. Acesso em 05 abr. 2021.

FUNDAÇÃO VANZOLINI. c2015. Disponível em https://vanzolini.org.br/. Acesso em 25 abr. 2021

GONÇALVES, J. C. S.; DUARTE, D. H. S. Arquitetura sustentável: uma integração entre ambiente, projeto e tecnologia em experiências de pesquisa, prática e ensino. Ambiente Construído, Porto Alegre, v. 6, n. 4, p. 51-81, out./dez. 2006. Disponível em: https://seer.ufrgs.br/ambienteconstruido/article/view/3720. Acesso em: 05 abr. 2021.

GREEN BUILDING COUNCIL BRASIL. c2021. Disponível em: https://www.gbcbrasil.org.br/. Acesso em 20 abr. 2021.

GRUNBERG, P. R. M.; MEDEIROS, M. H. F. de; TAVARES, S. F.. Certificação ambiental de habitações: comparação entre LEED for Homes, Processo Aqua e Selo Casa Azul. Ambiente \& Sociedade, São Paulo, v. 17, n. 2, p. 195-214, Jun. $\quad 2014$. Disponivel em: http://www.scielo.br/scielo.php?script=sci_arttext\&pid=S1414753X2014000200013\&lng=en\&nrm=iso. Acesso em: 01 maio 2021.

JOHN, V. M.. Reciclagem de resíduos na construção civil: Contribuição para metodologia de pesquisa e desenvolvimento. São Paulo, 2000. 113p. Tese (Livre Docência) - Escola Politécnica da Universidade de São Paulo. Departamento de Engenharia de Construção Civil.

KIM, J-J.; RIGDON, B. Introduction to Sustainable Design. Ann Arbor: University of Michigan, 1998. Disponível em: https://www.academia.edu/37915628/Introduction_to_Sustainable_Design_Sustainable_Architecture_Module_Int roduction_to_Sustainable_Design. Acesso em 05 abr. 2021.

KLINTOWITZ, D.. Por que o Programa Minha Casa Minha Vida só poderia acontecer em um governo petista?. Cadernos Metrólole, São Paulo, v. 18, n. 35, p. 165-190, Abr. 2016 . Disponível em: http://www.scielo.br/scielo.php?script=sci_arttext\&pid=S2236-99962016000100165\&lng=en\&nrm=iso. Acesso em: 05 maio 2021.

PINTO, T. P.. Metodologia para a gestão diferenciada de resíduos sólidos da construção urbana. São Paulo, v. 189, 1999. Tese (Doutorado) - Escola Politécnica da Universidade de São Paulo. Departamento de Engenharia de Construção Civil.

PRECON. Precon Engenharia. Método Construtivo: SHP - Solução Habitacional Precon, c2019. Disponível em: https://meuprecon.com.br/metodo-construtivo. Acesso em 03 maio 2021.

ROTH, C. das G.; GARCIAS, C. M. Construção Civil e a Degradação Ambiental. Desenvolvimento em Questão, [S. I.], v. 7, n. 13, p. 111-128, 2011. DOI: 10.21527/2237-6453.2009.13.111-128. Disponível em: https://revistas.unijui.edu.br/index.php/desenvolvimentoemquestao/article/view/169. Acesso em: 6 abr. 2021.

SANTOS, M. de S. dos. Certificação do Selo Casa Azul e sua aplicabilidade em projetos multifamiliares financiados pelo Programa Minha Casa Minha Vida. 2017. 113 f. Monografia (Graduação) - Curso de Engenharia Civil, Universidade do Sul de Santa Catarina, Tubarão, 2017. Disponível em: https://riuni.unisul.br/bitstream/handle/12345/2157/PDF\%20A\%20Morgana\%20de\%20Souza\%20dos\%20Santos.pd f?sequence=1\&isAllowed=y. Acesso em: 02 maio 2021.

SILVA, L. E.. O custo do certificado ambiental selo casa azul em um projeto residencial unifamiliar. 2017. Monografia (Graduação). Engenharia Civil, Universidade Federal do Rio de Janeiro, Macaé, 2017. Disponível em: http://engenharias.macae.ufrj.br/images/testetcc/2017/TCC---Lucas-Encarnacao.pdf. Acesso em 28 abr. 2021. 